\title{
Oral propranolol for the treatment of infantile haemangiomas in Singapore
}

Joanne Mui Ching $\underline{\operatorname{Tan}}{ }^{1}$, MMed, MRCPCH, Hwee Woon $\underline{\mathrm{Lim}^{2}}$, MRCPCH, GDFM, Mark Jean-Aan $\underline{K o h}^{3}$, MRCPCH, FAMS

INTRODUCTION Infantile haemangiomas $(\mathrm{IH})$ are the most common vascular tumours in childhood. Over the past decade, treatment of IH has been revolutionised by the discovery of the effectiveness of beta-blockers in its treatment. We review our hospital's experience with oral propranolol in the treatment of IH in an Asian population.

METHODS We performed a retrospective review of the medical records and clinical photos of paediatric patients with IH treated with propranolol in a tertiary paediatric hospital in Singapore from January 2010 to February 2015.

RESULTS A total of 88 patients with IH treated with propranolol were identified over a five-year period, with 79 patients included in the final analysis. There was a predominance of female patients $(75.9 \%)$ and preterm infants (41.8\%) in our study population. The head and neck (65.8\%), especially the orbital or preorbital region (45.6\%), were the most common lesion sites in our cohort of patients. Mean age of onset was $2.3 \pm 4.5$ weeks of age, and mean age of starting propranolol treatment was $7.7 \pm 10.5$ weeks of age. $44.3 \%$ of patients experienced $>75 \%$ improvement, while $29.1 \%$ experienced improvement of $50 \%-75 \%$. Response to treatment was influenced by the age of starting treatment.

CONCLUSION Our study provides further evidence of the efficacy and safety of propranolol in the treatment of IH in an Asian population. Early treatment is recommended for optimal results.

Keywords: infantile haemangioma, propranolol

\section{INTRODUCTION}

Infantile haemangiomas $(\mathrm{IH})$ are the most common paediatric vascular tumours, occurring in $2 \%-4 \%$ of infants. ${ }^{(1-4)}$ They are more common in Caucasian, female and premature infants. ${ }^{(5,6)}$ Lesions are usually not present at birth and become evident during the first 3-6 weeks of life. This is followed by rapid growth during the first 4-5 months. ${ }^{(7)}$ Although $\mathrm{IH}$ have the unique characteristic of self-involution after the first year of life, up to $10 \%$ of $\mathrm{IH}$ cases result in complications such as ulceration, bleeding, infection, airway obstruction and visual disturbance, warranting consideration for intervention. ${ }^{(8)}$

Historically, treatment options for complicated $\mathrm{IH}$ included intralesional and systemic corticosteroids, chemotherapeutic agents, laser therapy and surgical intervention. ${ }^{(9)}$ These treatments potentially have considerable side effects. Propranolol is a non-selective beta blocker that is commonly used in patients with cardiac and thyroid conditions. In 2008, Léauté-Labrèze et al from the Bordeaux Children's Hospital, France, reported their serendipitous observation of the rapid regression of $\mathrm{IH}$ in cardiac patients treated with propranolol. ${ }^{(10)}$ Since then, propranolol has been the mainstay of treatment for complicated $\mathrm{IH}$ worldwide.

We reviewed the efficacy and safety of oral propranolol for the treatment of complicated $\mathrm{IH}$ in a tertiary paediatric hospital in Singapore with a mostly Asian population. Given that most published studies were largely conducted among a Caucasian population, we aimed to investigate for any biological factors that may affect the efficacy of treatment in our Asian population.

\section{METHODS}

We performed a retrospective descriptive study of paediatric patients with $\mathrm{IH}$ treated with propranolol in a tertiary paediatric hospital in Singapore over five years, from January 2010 to February 2015. The study was approved by the hospital's ethics committee. All paediatric patients with $\mathrm{IH}$ who were treated with propranolol were identified from pharmacy records. Patients who were not treated with propranolol or received other treatment modalities such as laser therapy were not included in this study.

Patients were commenced on propranolol based on clinical indications, at the discretion of the attending dermatologist. Common indications included functional impairment, ulceration and large facial IH with potential cosmetic disfigurement. All babies below three months of age or with significant comorbidities were monitored in the paediatric inpatient ward for at least 24 hours upon commencement of propranolol. Regular monitoring of blood pressure and heart rate was performed during the admission for approximately 24 hours. Pre-feed blood sugar level was also recorded at least once during the admission. Incremental dosages of propranolol were administered, starting from $1 \mathrm{mg} / \mathrm{kg} /$ day. Most babies were discharged on $2 \mathrm{mg} / \mathrm{kg} /$ day of propranolol, in three divided doses, at least six hours apart. Follow-up was scheduled after 2-4 weeks, with gradual increment of propranolol up to $3 \mathrm{mg} / \mathrm{kg} /$ day in two or three divided doses. For babies who were more than three months of age and did not have other comorbidities, treatment was initiated in the outpatient paediatric dermatology clinic. Baseline electrocardiography, heart rate and blood pressure were recorded prior to commencement of the first dose of propranolol ( $1 \mathrm{mg} / \mathrm{kg} /$ day). Patients were observed

${ }^{1}$ General Paediatrics, KK Women's and Children's Hospital, ${ }^{2}$ Dr Lim Lean Huat and Associates Pte Ltd, '3ermatology Service, KK Women's and Children's Hospital, Singapore Correspondence: Dr Joanne Mui Ching Tan, Consultant, General Paediatrics, KK Women's and Children's Hospital, 100 Bukit Timah Road, Singapore 229899. joanne.tan.m.c@singhealth.com.sg 
in the clinic for two hours with monitoring of heart rate and blood pressure. Follow-up was scheduled every 1-2 weeks with gradual increase of propranolol up to $3 \mathrm{mg} / \mathrm{kg} /$ day.

Data collection was performed via reviewing of case notes as well as serial digital photographs taken at each visit. The degree of improvement was assessed by the attending dermatologist based on clinical assessment, in comparison with earlier photographs. Parameters assessed were improvement in size, colour and elevation of $\mathrm{IH}$.

All demographic and clinical characteristics of patients were summarised as mean \pm standard deviation and frequency (percentage) for continuous data and categorical data, respectively. Efficacy of propranolol was judged based on improvement after treatment. Patients were categorised based on improvement status as $>75 \%$ improvement, $50 \%-75 \%$ improvement, $25 \%-50 \%$ improvement and $<25 \%$ improvement. These four groups were compared based on $F$-test and chi-square test for continuous data and categorical data, respectively. A p-value $<0.05$ indicated statistical significance for all tests. SAS version 9.3 software (SAS Institute, Cary, NC, USA) was used for the analysis.

\section{RESULTS}

A total of 88 patients with $\mathrm{IH}$ who were treated with propranolol were identified from the database. Table I summarises the baseline demographics of the patients. $9(10.2 \%)$ patients were not analysed due to lack of photographic documentation. Among the 79 patients analysed, there was a predominance of female infants $(75.9 \%, n=60)$, with $19(24.1 \%)$ male infants. The racial distribution of our patients reflected Singapore's multiethnic population: $59.5 \%$ Chinese, $11.4 \%$ Malay, $7.6 \%$ Indian and $21.5 \%$ of other races. A significant proportion (41.8\%) were preterm infants of $<37$ weeks' gestation.

Table II summarises the characteristics of the $\mathrm{IH}$ in our cohort. The most commonly affected site in these patients with $\mathrm{IH}$ treated with propranolol was the head or neck region (65.8\%), followed by the trunk and groin (11.4\%) and upper limbs (8.9\%). Within the head and neck region, the orbital and periorbital regions $(45.6 \%)$ were most commonly affected, followed by the oral cavity (15.8\%) and parotid region (15.8\%) and cheeks (12.2\%). $49.4 \%$ of all lesions had only a superficial component, $34.2 \%$ had only a deep component, and $16.5 \%$ were mixed with both superficial and deep components. The mean age of onset was 2.3 \pm 4.5 weeks of age, mean age of starting propranolol was $7.7 \pm$ 10.5 weeks, and mean time of response to treatment was $3.3 \pm$ 3.3 weeks. The mean maximum propranolol dose administered was $2.2 \pm 0.5 \mathrm{mg} / \mathrm{kg} /$ day. The mean duration of treatment was $11.0 \pm 6.7$ months.

With regard to response to treatment, $44.3 \%$ of patients experienced $>75 \%$ improvement, while $29.1 \%$ experienced improvement of $50 \%-75 \%$. Only $26.6 \%$ of patients had $<50 \%$ improvement. Patients who experienced more significant improvement had been started on propranolol earlier in life. Patients treated before one year of age also responded better than those treated after one year of age $(p=0.002)$. For the 67 patients who started treatment before one year of age, $49.3 \%$
Table I. Characteristics of the patients $(n=79)$.

\begin{tabular}{|ll|}
\hline Characteristic & No. (\%) \\
\hline Gender & $19(24.1)$ \\
\hline Male & $60(75.9)$ \\
\hline Female & \\
\hline Ethnicity & $9(11.4)$ \\
\hline Malay & $47(59.5)$ \\
\hline Chinese & $6(7.6)$ \\
\hline Indian & $17(21.5)$ \\
\hline Others & $39(49.4)$ \\
\hline Gestation & $33(41.8)$ \\
\hline Term & $7(8.9)$ \\
\hline Preterm & \\
\hline Unknown & \\
\hline
\end{tabular}

Table II. Clinical characteristics of the haemangiomas $(\mathbf{n}=79)$.

\begin{tabular}{|ll|}
\hline Parameter & No. (\%) \\
\hline Location & $52(65.8)$ \\
\hline Head and neck & $9(11.4)$ \\
\hline Trunk and groin & $7(8.9)$ \\
\hline Upper limbs & $3(3.8)$ \\
\hline Lower limbs & $3(3.8)$ \\
\hline Airways & $2(2.5)$ \\
\hline Head and neck + trunk and groin & $1(1.3)$ \\
\hline Head and neck + airways & $2(2.5)$ \\
\hline Trunk and groin + upper limbs & $60(75.9)$ \\
\hline No. of haemangiomas & $19(24.1)$ \\
\hline Single & \\
\hline Multiple & $27(34.2)$ \\
\hline Depth & $39(49.4)$ \\
\hline Deep & $13(16.5)$ \\
\hline Superficial & \\
\hline Mixed & \\
\hline
\end{tabular}

experienced $>75 \%$ improvement, $29.9 \%$ experienced $50 \%-75 \%$ improvement, $17.9 \%$ experienced $25 \%-50 \%$ improvement and only $2.2 \%$ had $<25 \%$ improvement. In contrast, in the 12 patients who started treatment after one year of age, up to $41.6 \%$ experienced $<25 \%$ improvement, $16.7 \%$ had $25 \%-50 \%$ improvement, $25.0 \%$ experienced $50 \%-75 \%$ improvement and only $16.7 \%$ experienced $>75 \%$ improvement. The response to propranolol was not influenced by gestational age $(p=0.7150)$, gender $(p=0.7367)$, age of onset $(p=0.7990)$, location $(p=0.1198)$, depth $(p=0.2328)$, size $(p=0.1952)$ or number of $\mathrm{IH}(\mathrm{p}=0.2642)$.

Of note, there were two patients with PELVIS (perineal $\mathrm{IH}$, external genital malformations, lipomyelomeningocoele, vesicorenal abnormalities, imperforate anus and skin tag) syndrome and one patient with PHACES (posterior fossa brain malformations, segmental facial haemangiomas, arterial anomalies, cardiac abnormalities and coarctation of the aorta, eye abnormalities, and sternal cleft or supraumbilical raphe) syndrome. All three demonstrated good response, with $>75 \%$ 
Table III. Factors associated with degree of improvement following propranolol use.

\begin{tabular}{|c|c|c|c|c|c|}
\hline \multirow[t]{2}{*}{ Characteristic } & \multicolumn{4}{|c|}{ Improvement } & \multirow[t]{2}{*}{ p-value } \\
\hline & $>75 \%(n=35)$ & $50 \%-75 \%(n=23)$ & $25 \%-50 \%(n=14)$ & $<25 \%(n=7)$ & \\
\hline $\begin{array}{l}\text { Haemangioma size in largest } \\
\text { diameter* ( } \mathrm{mm})\end{array}$ & $40.0 \pm 27.4$ & $33.9 \pm 17.2$ & $46.0 \pm 22.7$ & $23.3 \pm 9.1$ & 0.1952 \\
\hline Time to response* (wk) & $3.5 \pm 3.7$ & $3.4 \pm 2.8$ & $2.8 \pm 2.2$ & $3.4 \pm 4.6$ & 0.7138 \\
\hline Age at start of treatment & & & & & 0.002 \\
\hline$>12 \mathrm{mth}$ & $2(5.7)$ & $3(13.0)$ & $2(14.3)$ & $5(71.4)$ & \\
\hline No. of haemangiomas & & & & & 0.2642 \\
\hline Single & $11(31.4)$ & $4(17.4)$ & $4(28.6)$ & $0(0)$ & \\
\hline Multiple & $24(68.6)$ & $19(82.6)$ & $10(71.4)$ & $7(100.0)$ & \\
\hline
\end{tabular}

Categorical data is presented as no. (\%). ${ }^{*}$ Data is presented as mean \pm standard deviation.
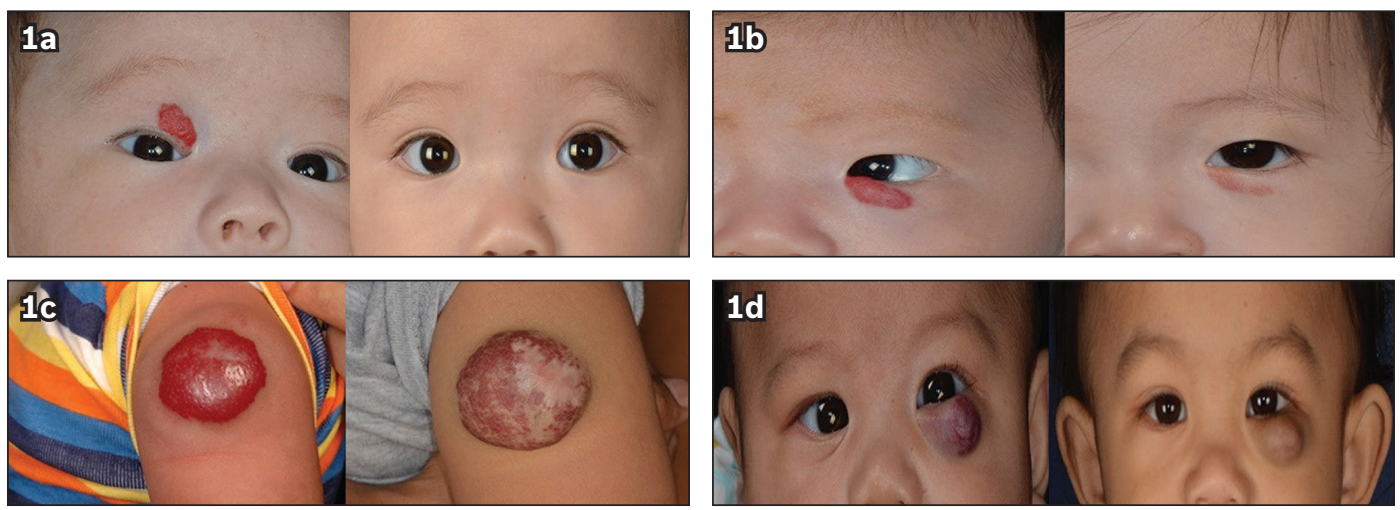

Fig. 1 Photographs show haemangiomas with (a) > 75\%; (b) $50 \%-75 \%$; (c) $25 \%-50 \%$; and (d) $<25 \%$ of improvement after treatment with propranolol.

improvement on treatment with propranolol. Additionally, $24.0 \%$ of patients had ulcerated $\mathrm{IH}$ and all improved with propranolol. For IH involving airways, response to treatment was assessed using radiology imaging. Table III summarises the factors associated with improvement following propranolol treatment. Fig. 1 provides examples of our patients with different degrees of improvement of $\mathrm{IH}$ on treatment with propranolol.

Data on side effects was collected via interviews with parents during each routine consultation by the attending dermatologist. There was a low incidence of side effects reported, which included sleep disruption in two patients, lethargy in one patient and bronchospasm in four patients. Two patients developed recurrent wheeze and required discontinuation of propranolol, after 12 months of treatment for one patient and after four months for the second. There were no reported episodes of hypotension, bradycardia or hypoglycaemia in our cohort.

\section{DISCUSSION}

Propranolol has traditionally been used in the paediatric population primarily for the treatment or prevention of cardiac arrhythmias, hypertension, outflow obstructions in congenital heart disease, and hypertrophic cardiomyopathy, at doses of as high as $8 \mathrm{mg} / \mathrm{kg} /$ day. Its antihypertensive effects result from decreased heart rate, decreased cardiac contractility, inhibition of renin release by the kidneys, and decreased sympathetic tone. It has been shown that in the pathogenesis of $\mathrm{IH}$, elevated expression of pro-angiogenic factors, such as vascular endothelial growth factor, basic fibroblast growth factor and proliferating cell nuclear antigen, can stimulate endothelial growth and lead to dysregulated angiogenesis. ${ }^{(11)}$ The overexpression of the glucose transporter 1 (GLUT-1) protein may also play a role in the pathogenesis of $\mathrm{IH} .{ }^{(12)}$ The mechanism of action of propranolol in the treatment of $\mathrm{IH}$ has yet to be clearly elucidated. Proposed hypotheses include vasoconstriction, decreased renin production, inhibition of angiogenesis, decreased plasmalemmal expression of GLUT-1, and stimulation of apoptosis. ${ }^{(13)}$

Similar to observations from other studies, our study found that early treatment with propranolol, especially in patients below one year of age, was associated with better response and degree of improvement. ${ }^{(14)}$ However, a retrospective review of 18 patients by Vivas-Colmenares et al reported a favourable response beyond the proliferation phase of $\mathrm{IH}$, with complete response in $72.2 \%$ of patients and partial response in $27.8 \% .{ }^{(15)}$ This suggests a further beneficial effect of propranolol on $\mathrm{IH}$ if it is commenced beyond the proliferative phase. Other than early initiation of treatment, no other factors have been found to be associated with greater efficacy of propranolol in our study population.

In a study by Sans et al, the mean duration of therapy was six months, with a range of $2-10$ months. ${ }^{(16)}$ Siegfried et al proposed that propranolol should be gradually tapered over a period of two weeks. ${ }^{(17)}$ Chik et al proposed a treatment duration of 4-6 months, with a gradual $25 \%$ weekly decrease in propranolol dosage over four weeks. ${ }^{(18)}$ In a meta-analysis conducted to analyse the safety profile and efficacy of propranolol 
among Chinese patients with $\mathrm{IH}$, the mean age at initiation of propranolol was 4.7 months, with response noted within 24 hours on an average dose of $2 \mathrm{mg} / \mathrm{kg} /$ day. ${ }^{(19)}$ Similarly, a more recent study by Léauté-Labrèze et al showed that propranolol at $3 \mathrm{mg} / \mathrm{kg} /$ day for six months was effective in the treatment of infantile haemangioma. ${ }^{(20)}$ In our cohort, the mean duration of treatment was $11.0 \pm 6.7$ months. Unfortunately, data on recurrence was not available for our study. We also propose a treatment duration of at least six months up to about one year of age, based on our experience with the current cohort of patients. There is no consensus, however, on whether the drug should be decreased over a duration or stopped completely. At our centre, propranolol dosage is decreased over a duration of 1-2 months to observe for recurrence.

Known adverse events associated with propranolol, such as hypoglycaemia, hypotension, bradycardia and bronchospasm, occur infrequently. ${ }^{(20)}$ Apart from bronchospasm occurring in four of our patients, none of them developed the more severe side effects of hypoglycaemia, hypotension or bradycardia, suggesting a very good safety profile at doses of less than $3 \mathrm{mg} / \mathrm{kg} /$ day. Milder side effects such as sleep disturbance as well as cool hands and feet do not require cessation of treatment.

Limitations of this study include the lack of a validated assessment for the evolution of infantile haemangiomas. Assessment of the degree of improvement was done by the attending dermatologist in comparison with previous photographic records, and thus there may be a risk of subjective bias. As this was a retrospective study, there could have been undocumented or missing data on treatment response as well as side effects. Furthermore, despite the five-year study period, the study population was relatively small.

In conclusion, our review reinforces results from previous studies that early treatment of complicated $\mathrm{IH}$ with propranolol is equally efficacious and safe in Asian populations. Given the favourable risk-benefit profile, propranolol should be the firstline therapy for infantile haemangiomas that require treatment.

\section{REFERENCES}

1. Frieden IJ, Eichenfield LF, Esterly NB, Geronemus R, Mallory SB. Guidelines of care for hemangiomas of infancy. American Academy of Dermatology Guidelines/Outcomes Committee. J Am Acad Dermatol 1997; 37:631-7.

2. Kilcline C, Frieden IJ. Infantile hemangiomas: how common are they? A systematic review of the medical literature. Pediatr Dermatol 2008; 25:168-73.

3. Hoornweg MJ, Smeulders M], van der Horst CM. [Prevalence and characteristics of haemangiomas in young children]. Ned Tijdschr Geneeskd 2005; 149:2455-8. Dutch

4. Munden A, Butschek R, Tom WL, et al. Prospective study of infantile haemangiomas: incidence, clinical characteristics and association with placental anomalies. Br J Dermatol 2014; 170:907-13.

5. Schwartz RA, Sidor MI, Musumeci ML, Lin RL, Micali G. Infantile haemangiomas: a challenge in paediatric dermatology. J Eur Acad Dermatol Venereol 2009; 24:631-8.

6. Storch $\mathrm{CH}$, Hoeger PH. Propranolol for infantile haemangiomas: insights into the molecular mechanisms of action. Br J Dermatol 2010; 163:269-74.

7. Chang LC, Haggstrom AN, Drolet BA, et al; Hemangioma Investigator Group. Growth characteristics of infantile haemangiomas: implications for management. Pediatrics 2008; 122:360-7.

8. Starkey E, Shahidullah H. Propranolol for infantile haemangiomas: a review. Arch Dis Child 2011; 96:890-3.

9. Leonardi-Bee J, Batta K, O’Brien C, Bath-Hextall FJ. Interventions for infantile haemangiomas (strawberry birthmarks) of the skin. Cochrane Database Syst Rev 2011; (5):CD006545.

10. Léauté-Labrèze $C$, Dumas de la Roque $E$, Hubiche $T$, et al. Propranolol for severe hemangiomas of infancy. N Engl J Med 2008; 358:2649-51.

11. Takahashi K, Mulliken JB, Kozakewich HP, et al. Cellular markers that distinguish the phases of hemangioma during infancy and childhood. J Clin Invest 1994; 93:2357-64.

12. North PE, Waner M, Mizeracki A, Mihm MC Jr. GLUT1: a newly discovered immunohistochemical marker for juvenile hemangiomas. Hum Pathol 2000; 31:11-22.

13. Sommers Smith SK, Smith DM. Beta blockade induces apoptosis in cultured capillary endothelial cells. In Vitro Cell Dev Biol Anim 2002; 38:298-304.

14. McGee P, Miller S, Black C, Hoey S. Propranolol for infantile haemangioma: a review of current dosing regime in a regional paediatric hospital. Ulster Med J 2013; 82:16-20.

15. Vivas-Colmenares GV, Bernabeu-Wittel J, Alonso-Arroyo V, Matute de Cardenas JA, Fernandez-Pineda I. Effectiveness of propranolol in the treatment of infantile haemangioma beyond the proliferation phase. Pediatr Dermatol 2015; 32:348-52.

16. Sans V, de la Roque ED, Berge J, et al. Propranolol for severe infantile hemangiomas: follow-up report. Pediatrics 2009; 124:e423-31.

17. Siegfried EC, Keenan WJ, Al-Jureidini S. More on propranolol for hemangiomas of infancy. N Engl J Med 2008; 359:2846.

18. Chik KK, Luk CK, Chan HB, Tan HY. Use of propranolol in infantile haemangioma among Chinese children. Hong Kong Med J 2010; 16:341-6.

19. Li LL, Yan L, Luo MX, et al. Propranolol in the treatment of infantile hemangiomas: a meta-analysis in Chinese patients. Pediatr Dermatol 2015; 32:e210-4.

20. Léauté-Labréze C, Hoeger P, Mazereeuw-Hautier J, et al. A randomized controlled trial of oral propranolol in infantile hemangioma. N Engl J Med 2015; 372:735-46. 